\title{
УСЛОВИЯ СОЗДАНИЯ
}

ПРОФЕССИОНАЛЬНО ВОСПИТЫВАЮЩЕЙ СРЕДЫ ДЛЯ СТУДЕНТОВ

\section{С ОСОБЫМИ ОБРАЗОВАТЕЛЬНЫМИ ПОТРЕБНОСТЯМИ}

\author{
Т.Ю. Скамьянова (Пермь, Красноярск)
}

\section{Аннотация}

Проблема и цель. Актуальность проблемы успешной адаптации обучающихся с особыми образовательными потребностями (ООП) к обучению в техническом вузе определена требованием формирования профессиональных компетенций студентов, заложенным в нормативных документах, в том числе конкурентоспособностью таких лиц на мировом рынке труда и «способностью выполнять высокотехнологичный инновационный менеджмент».

Цель статьи - обосновать педагогические условия, способствующие формированию профессиональной культуры студентов с ООП, включающей умение укреплять свое здоровье, что способствует их успешной профессиональной адаптации в целом и повышению учебной продуктивности в частности.

Обзор научной литературы по проблеме показал, что профессиональная адаптация студентов с особыми образовательными потребностями в высшем инженерном образовательном учреждении учеными-педагогами не изучалась.

Методологию исследования составили антропологический подход в образовании (К.Д. Ушинский, О.С. Гребенюк, Н.М. Борытко и др.), а также идеи здоровьесберегающего, компетентностного, целостного и системного подходов осуществления психолого-педагогического исследования.
Результаты исследования. В статье представлена модель процесса формирования профессиональной культуры студентов с ООП и определены условия создания профессионально воспитывающей среды для них с использованием педагогических технологий контекстного обучения, учения через обучение и разноуровневого обучения. Экспериментальная проверка предложенных педагогических условий подтвердила эффективность такого взаимодействия между субъектами педагогического процесса.

Заключение. Предложенные педагогические условия действительно способствуют формированию профессиональной культуры у студентов с особыми образовательными потребностями, в том числе определенных способов поведения, позволяющих им справляться с адаптационными трудностями, укреплять здоровье и успешно учиться. Из 228 респондентов, участвовавших в исследовании, об улучшении самочувствия сообщают до одной трети студентов с ООП. Выполненное исследование убедило нас в том, что для студентов с ООП необходимо создавать профессионально воспитывающую среду.

Ключевые слова: студенты с особыми образовательными потребностями, модель, формирование, профессиональная адаптация к обучению, педагогические технологии, профессиональная культура.

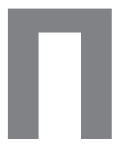
остановка проблемы. Актуальность проблемы успешной адаптации обучающихся с особыми образовательными потребностями (ООП) к обучению в техническом вузе определена требованием формирования профессиональных компетенций у студентов, заложенным в нормативных документах ${ }^{1,2}$, в том числе конкурентоспособностью таких лиц на мировом рынке труда и

Федеральный закон Российской Федерации «Об образова нии» от 29.12.2012 № 273-Ф3: принят Гос. Думой Федер. Собр. Рос. Федерации 21.12.2012: одобр. Советом Федерации Федер Собр. Рос. Федерации 26.12.2012.

2 Приказ Министерства образования и науки России от 25 января 2010 г. № 66. Об утверждении и введении в действие федерального государственного образовательного стандарта высшего профессионального образования... [ПК-16]. 
пособностью выполнять высокотехнологичный инновационный менеджмент.

Цель статьи - обосновать педагогические условия, способствующие формированию профессиональной культуры студентов с ООП, включающей умение укреплять здоровье, что способствует их успешной профессиональной адаптации, в целом, и повышению учебной продуктивности, в частности.

Обзор научной литературы по проблеме. Здоровьесберегающий подход при организации любой профессиональной, в том числе учебной, деятельности предполагает различные виды отдыха: ежедневный, еженедельный и ежегодный. Однако для части обучающихся в полной мере эти виды отдыха недоступны. Речь идет о студентах с особыми образовательными потребностями. Они испытывают такие большие интеллектуальные нагрузки, которые приводят к систематическому превышению ими норм времени учебной подготовки [Ивахненко, 2013, с. 102]. Попав в новую социальную среду, такие обучающиеся нередко испытывают личностные конфликты [Никуленкова, 2015, с. 148]. Эти факторы являются причиной обострения хронических заболеваний студентов с ООП и появления новых недомоганий [Шац и др., 2016, с. 316], что нередко приводит молодого человека к решению о смене специальности.

В первой трети семнадцатого века чешский педагог Ян Амос Коменский обосновал «правила для продолжения жизни» (Великая дидактика, лат. 1638), в которых описал условия предохранения тела от болезней [Коменский, 1982, гл. XV]. В Великой дидактике он описал и методы обучения детей, склонных к переутомлению [Коменский, 1982, с. 310]. Английский педагог Джон Локк, также имевший медицинское образование [Локк, 2000, с.13], советовал соотносить интенсивность «занятий с мерой... здоровья или болезненного состояния» [Локк, 2000, c. 202] обучаемого. Адольф Дистервег предупреждал, что чрезмерное умственное напряжение может повлечь за собой серьезное заболевание юноши [Дистервег, 1956, с. 124].
Как показали наблюдения К.Д. Ушинского, длительно или часто болеющий человек «устает скоро и отдыхает очень медленно» [Ушинский, 1950, с. 87]. Поэтому, считал педагог, от наставника требуется особое умение подбирать виды целесообразного взаимодействия с воспитанником, а также содержание обучения, посильное для понимания и самостоятельных суждений того, кого он учит [Ушинский, 1949, с. 249]. Государственный деятель конца XIX - начала XX веков К.П. Победоносцев писал о престиже профессии учителя и необходимости того, чтобы «лучшие люди России» посвящали себя учительскому служению [Беленчук, 2005, с. 118]. В.И. Лубовский изучал учебные возможности детей с недостатками развития и в семидесятых годах XX века ввел в научный оборот термин «особые образовательные потребности» [Лубовский, 2013, с. 62]. В настоящее время в соответствии с законом об образовании в РФ круг лиц, которым необходимы особые условия профессионального обучения, значительно расширен [ФЗ РФ «Об образовании» $\left.{ }^{3}, 2012\right]$. Поэтому исследования современных ученых, представляющих педагогические позиции антропологического подхода в образовании и разрабатывающих инклюзивные условия обучения для студентов с особыми образовательными потребностями (О.С. Гребенюк, Н.М. Борытко А.В. Мудрик, М.Ю. Бухаркина, С.М. Юсфин, Х. Скилз), востребованы педагогическим сообществом.

Закон об образовании в РФ № 273-Ф3 от 29.12.2012 гарантирует всем обучающимся предоставление условий для обучения, учитывающих особенности их психофизического развития и состояния здоровья [ФЗ РФ «Об образовании» $\left.{ }^{4}, 2012\right]$. Для лиц с хроническими заболеваниями, длительно и часто болеющих существуют рекомендации по здоровьесбережению и комплексному сопровождению образовательного процесса [Методические

\footnotetext{
Федеральный закон Российской Федерации «Об образовании» от 29.12.2012 № 273-Ф3: принят Гос. Думой Федер. Собр. Рос. Федерации 21.12.2012: одобр. Советом Федерации Федер. Собр. Рос. Федерации 26.12.2012.

4 Там же. Ст. 34.
} 
рекомендации $\left.{ }^{5}, 2014\right]$, предусмотрена организация медицинского «динамического наблюдения» [Методические рекомендации 6 , 2014, с. 19]. Значительное влияние на психофизическое состояние студента оказывают наличие хронического заболевания или инвалидности, потеря родителей, изменение социального статуса. Поэтому в настоящее время вопросы наставничества и консультирования студентов с особыми образовательными потребностями широко обсуждаются международной педагогической общественностью. Так, например, в университете города Бингемтон, сообщает Эрик Скоттс, в штате Нью-Йорк подготовлена специальная программа для повышения учебной успешности таких студентов [Cotts, 2016, р. 3]. Изучаются различия между студентами с особыми образовательными потребностями и практически здоровыми студентами [Mehr, Daltry, 2016, р. 147] для того, как поясняет Кристин Мер, чтобы выявить меняющиеся потребности этих лиц и пересмотреть стратегии их поддержки координаторами. Такие исследования проводятся в Великобритании [Koca-Atabey, 2016, с. 137]. Получение социально-педагогической и психологической помощи, бесплатной психолого-медикопедагогической коррекции гарантирует студентам и закон об образовании в Российской Федерации № 273-ФЗ [ФЗ РФ «Об образовании»”, 2012, ст. 34, п. 1, п.п. 2].

Законом № 273-ФЗ для студентов с ООП, относящихся к лицам с ограниченными возможностями здоровья (с нарушениями слуха, зрения и др.) и особенностями развития, например с задержкой психического развития, предусмотрены коррекционные схемы обучения, с помощью которых обучающийся может изба-

\footnotetext{
Методические рекомендации по организации образовательного процесса для обучения инвалидов и лиц с ограниченными возможностями здоровья в образовательных организациях высшего образования, в том числе оснащенности образовательного процесса. № АК-44/05 вн, от 08.04.2014 г. / Министерство образования и науки Российской Федерации. М., 2014. 19 с.

6 Там же. С. 19.

7 Федеральный закон Российской Федерации «Об образовании» от 29.12.2012 № 273-Ф3: принят Гос. Думой Федер. Собр. Рос. Федерации 21.12.2012: одобр. Советом Федерации Федер. Собр. Рос. Федерации 26.12.2012.
}

виться от дефекта или существенно уменьшить его влияние [ФЗ РФ «Об образовании» ${ }^{8}, 2012$, гл. 11, ст. 79]. Комплексное сопровождение образовательного процесса для лиц с хроническими заболеваниями, длительно и часто болеющих включает медицинскую, социальную, педагогическую и психологическую помощь [Mетодические рекомендации ${ }^{9}, 2014$, с. 16]. Однако анализ моделей педагогического сопровождения студентов с ООП, представленных в работах А.Г. Станевского, В.З. Кантора, Л.В. Андреевой, Д.И. Бойкова, Е.Ф. Войлоковой и других исследователей показал, что эти модели не распространяются на лиц с хроническими заболеваниями, длительно и часто болеющих.

Методология (материалы и методы). Педагогические позиции антропологического подхода в образовании (К.Д. Ушинский, О.С. Гребенюк, Н.М. Борытко), наставничества и консультирования студентов с особыми образовательными потребностями, представленные в трудах по организации учебной деятельности обучающихся с разными учебными возможностями, состоянием здоровья и особенностями характера Я.А. Коменского, Дж. Локка, А. Дистервега, позволяют сделать следующий вывод. Педагогам высшей школы желательно разрабатывать инклюзивные условия обучения не только для студентов с хроническими заболеваниями, длительно и часто болеющих, но и для тех обучающихся, кто переживает потерю родителей, изменение социального статуса.

Научно-педагогическое исследование проблемы профессиональной адаптации студентов с ООП, относящихся к лицам с хроническими заболеваниями, длительно и часто болеющим, позволило нам представить его результаты в форме педагогической концепции. Концепция технического образования лиц с особыми

\footnotetext{
8 Федеральный закон Российской Федерации «Об образовании» от 29.12.2012 № 273-Ф3: принят Гос. Думой Федер. Собр. Рос. Федерации 21.12.2012: одобр. Советом Федерации Федер. Собр. Рос. Федерации 26.12.2012.

9 Методические рекомендации по организации образовательного процесса для обучения инвалидов и лиц с ограниченными возможностями здоровья в образовательных организациях высшего образования, в том числе оснащенности образовательного процесса. № АК-44/05 вн, от 08.04.2014 г. / Министерство образования и науки Российской Федерации. М., 2014. 19 с.
} 
образовательными потребностями предполагает, что в годы учебы такой студент начинает успешную реализацию профессиональной карьеры, для чего формирует профессиональную культуру, включающую умение укреплять здоровье. Ученый-педагог В.И. Загвязинский, исследуя профессиональную успешность практически здоровых участников педагогического процесса высшей школы, высказал эту идею в начале XXI века. Студентам с ООП, относящимся к лицам с хроническими заболеваниями, длительно и часто болеющим, либо утратившим свое благополучие, для осуществления содержательной карьеры необходима дополнительная индивидуализированная коррекция социальной и профессиональной адаптации, предполагающая участие сотрудников вуза (консультантов, наставников, координаторов) в решении проблем таких студентов в период их адаптации к учебной деятельности. Теоретико-методологические основания концепции, в том числе идеи теории педагогической праксиологии (А.Е. Марон, И.А. Колесникова и др.), закономерность между профессионализацией личности и содержанием профессиональной карьеры (Ю.П. Поваренков), принципы закономерности (В.А. Ситаров) представлены нами в публикациях результатов предыдущих исследований [Skamyanova, Kosolapova, 2017; Скамьянова, 2018, с. 165-166].

В данной статье выделим условия создания профессионально воспитывающей среды как «специальным образом подобранной системы мер» [Яковлев, 2006, с. 18], обеспечивающей продуктивность взаимодействия субъектов педагогического процесса.

Результаты исследования. Работа проводится в Пермском национальном исследовательском политехническом университете во исполнение требований Федерального закона об образовании в Российской Федерации от 29.12.2012.

Этапы программы исследования. Начальный этап для анализа спектра проблем таких студентов по материалам предыдущих исследований; второй этап для моделирования последовательности процесса формирования професси- ональной культуры студентов с ООП; третий этап для определения условий создания профессионально воспитывающей среды для студентов с ООП; четвертый этап для экспериментальной проверки выбранных условий; пятый этап для анализа результатов исследования.

В исследовании участвовали студенты с особыми образовательными потребностями первого и старших курсов шести факультетов: прикладной механики и математики (ФПММ) - 44+42 человека с первого курса; аэрокосмического (АКФ) - 50 человек с первого курса; механикотехнологического (МТФ) - 41 человек с первого курса бакалавриата и 8 человек с первого и второго курсов магистратуры; автодорожного факультета (АДФ) - 20 человек со второго курса бакалавриата; химико-технологического (ХТФ) 10 человек с третьего курса; гуманитарного (ГумФ) - 13 человек с четвертого курса.

Достоверность результатов исследования.

Исследование, результаты которого представлены в статье, продолжается с 01.09.2011. По состоянию на 08.09.2015 нами были опрошены 492 человека, почти все они участвовали в адаптационном взаимодействии. За 2015/16 учебный год, по состоянию на 16.08 .2016 , работали с педагогами системы адаптации еще 264 студента. В 2016/17 учебном году общее количество студентов, участвовавших в адаптационном взаимодействии, увеличилось еще на 316 человек, из них 171 человек участвовал в проекте «Педагогическое сотрудничество». Молодые люди учатся на всех девяти факультетах ПНИПУ, наблюдаются терапевтами и узкими специалистами, по свидетельству которых, большая часть студентов сохраняет свое здоровье, а около трети лиц даже укрепляют его. Представители администрации факультетов удовлетворены повышением учебной успешности своих студентов.

Характеристика студентов с ООП. Комплексное сопровождение образовательного процесса необходимо не только хроническим больным и некоторым категориям инвалидов. Ученые Шмитц Ж., Белокриницкая Т.Е. и др. отмечают, что большинство молодых матерей, вынашива- 
ющих плод, испытывают недомогание [Шмитц, 2008, с. 98; Белокриницкая, 2013, с. 103]. Наиболее опасным в этом отношении является первый триместр беременности. Ряд нормативных актов российского законодательства регулирует вопросы гигиены труда беременных женщин, их здоровья и возможности предоставления им времени для дополнительного отдыха $\left[\right.$ СанПиН. Гигиена труда ${ }^{10}$, Трудовой кодекс ${ }^{11}$ РФ и др.]. Учебную деятельность студентов-сирот регламентирует множество нормативных материалов [Сборник нормативных правовых документов $^{12}$, Сборник программно-методических материалов $^{13}$, Ф3 № 159-Ф3 $\left.{ }^{14}\right]$. Студент-сирота до достижения им 23 лет по законодательству имеет опекуна (законного представителя), выполнение обязанностей законного представителя этих студентов возлагается на администрацию высшего учебного заведения [Сборник нормативных правовых документов ${ }^{15}, 2006$, с. 8]. По мнению ученых-педагогов, сироты оказались в особо трудном положении и нуждаются в экстренной помощи, включающей, не только «динамическое наблюдение» за состоянием их здоровья, но и дополнительные психолого-педагогические меры [Мудрик, 2002, с. 173]. Следующей категорией студентов, которой закон гарантирует условия обучения, учитывающие особенности их психофизического развития [ФЗ РФ «Об образовании» ${ }^{16}, 2012$, ст. 34, п. 1, 2], являются лица,

${ }_{10}$ СанПиН 2.2.0.555-96. Гигиена труда. Гигиенические требования к условиям труда женщин. От 28.10.1996. № 32. Пункты 4.2.1. и 4.2.2.

11 Трудовой кодекс РФ. С. 254; 255; 261 и др. Принят Государственной Думой 21.12. 2001. Одобрен Советом Федерации 26.12. 2001 // Российская газета. № 256. 31.12.2001 г.

12 В добрый путь выпускник! Сборник нормативных правовых документов и методических материалов по вопросам защиты прав детей-сирот и детей, оставшихся без попечения родителей, лиц из их числа. Пермь: ПОНИЦАА, 2006. 72 с.

13 Дополнительная образовательная программа «Соучастие в судьбе»: сб. программно-методических материалов. Пермь: «ОТ и ДО», 2010. 64 с.

14 Федеральный закон № 159-Ф3 «О дополнительных гарантиях по социальной поддержке детей-сирот и детей, оставшихся без попечения родителей» от 21.12.1996 (ред. от 07.03.2018).

15 В добрый путь выпускник! Сборник нормативных правовых документов и методических материалов по вопросам защиты прав детей-сирот и детей, оставшихся без попечения родителей, лиц из их числа. Пермь: ПОНИЦАА, 2006. 72 с.

16 Федеральный закон Российской Федерации «Об образовании» от 29.12.2012 № 273-Ф3: принят Гос. Думой Федер. Собр. Рос. Федерации 21.12.2012: одобр. Советом Федерации Федер. Собр. Рос. Федерации 26.12.2012. склонные к переутомлению при интенсивных интеллектуальных нагрузках. О них пишут как педагоги высшей школы, так и наблюдающие их врачи. В.И. Циркин отмечает у лиц, склонных к переутомлению, дефицит внимания и гиперактивность, предлагает «меры борьбы с развивающимся утомлением» [Агаджанян и др., 2003, с. 429], Т.Б. Дмитриева считает, что таким студентам необходима специализированная медицинская помощь [Клиническая психиатрия $\left.{ }^{17}, 1998\right]$. Студенты зрелого возраста осознанно прибегают к комплексному сопровождению образовательного процесса. Интенсивные учебные нагрузки приводят таких лиц к хроническому переутомлению, являются причиной углубления личностных конфликтов студентов, отрицательно сказываются на их здоровье [Шац и др., 2016].

Проблема сохранения контингента таких студентов.

Студентам с ООП: лицам с хроническими заболеваниями, длительно и часто болеющим; беременным; сиротам; лицам, склонным к переутомлению при интенсивных интеллектуальных нагрузках; людям зрелого возраста - присущи черты, снижающие эффективность их учебной деятельности. Например, длительно и часто болеющие студенты нередко пропускают аудиторные занятия из-за госпитализации или амбулаторного лечения [Скамьянова, 2017, с. 368]. Поэтому студенты всех изучаемых нами категорий в подавляющем большинстве не укладываются в нормативные сроки учебного процесса [Пискун, 2013, с. 125; Скамьянова, 2012, с. 24]. Для того чтобы оказывать социально-педагогическую и психологическую помощь таким студентам, осуществлять эффективную психолого-медикопедагогическую коррекцию [ФЗ РФ «Об образовании» ${ }^{18}, 2012$, ст. 34, п. 1, п.п. 2] их социальной и учебной адаптации, необходимо определить причины слабой учебной успешности этих студентов. При отсутствии участия сотрудников

\footnotetext{
17 Клиническая психиатрия: пер. с англ. доп. / гл. ред. Т.Б. Дмитриева. М.: ГЭО ТАР МЕДИЦИНА,1998. 508 с.

18 Федеральный закон Российской Федерации «Об образовании» от 29.12.2012 № 273-Ф3: принят Гос. Думой Федер. Собр. Рос. Федерации 21.12.2012: одобр. Советом Федерации Федер. Собр. Рос. Федерации 26.12.2012.
} 
вуза (консультантов, наставников, координаторов) в решении проблем таких студентов в период их адаптации к учебной деятельности большинство студентов с ООП по разным причинам отчисляются с курса обучения.

Причины слабой учебной успешности студентов.

В сентябре 2015 года, имея сведения о большой выборке студентов с ООП, мы проанализировали причины их отставания в учебной деятельности от практически здоровых однокурсников. Наши предположения о том, что студенты с хроническими заболеваниями, длительно и часто болеющие часть времени тратят на посещение врачей и выполнение их предписаний, поэтому пропускают аудиторные занятия, подтвердились. Таких студентов оказалось чуть меньше 50 \%. Еще около трети студентов с ООП сообщали о своей слабой учебной подготовке. Часть студентов заявляли, что специальность, на которую они поступили, не нравится им; они хотели бы получать другую специальность [Skamyanova, Kosolapova, 2017, с. 155]. Диагностика студентов с ООП осуществляется нами постоянно, названные причины слабой успешности таких студентов характерны для всех последующих опросов.

Условия создания профессионально воспитывающей среды.

Согласно концепции технического образования лиц с ООП для успешной реализации своей профессиональной карьеры такой студент начиная с первого курса обучения формирует профессиональную культуру, включающую умение укреплять свое здоровье. Содержательное наполнение концепции, включающее механизмы, процедуры и средства ее практического применения, представлено на рис. 1. Логика развертывания общего содержания концепции - от общетеоретических положений к технологии использования в образовательном процессе - представлена в средней части рисунка.

Модель процесса формирования профессиональной культуры студентов с ООП позволяет представить последовательность его перехода из одного состояния в другое, изучить отдельные стороны его развития. В структуре про- цесса формирования профессиональной культуры выделены следующие этапы. Диагностический этап: совместное со студентом определение его интересов, склонностей, способностей, ценностно-целевых установок, возможностей и способов преодоления затруднений, препятствующих его саморазвитию [Борытко, 2005, с. 76]. Преобразующий этап: внутреннее содержание и закономерные связи в деятельности субъектов педагогического процесса, методы, приемы и особенности взаимодействия. Итоговый этап: обобщение, оценка и анализ полученных результатов.

Необходимо отметить, что процесс формирования профессиональной культуры - сложный, многоаспектный процесс. Поэтому для более полного его описания в структуре преобразующего этапа на рис. 1 представлен комплекс частных моделей [Яковлев, 2006, с. 126]. Например, реализуемая в рамках системы адаптации студентов с особыми образовательными потребностями к обучению в техническом вузе [Скамьянова, 2016, с. 251] модель становления учебной адаптированности студента, представленная на рис. 2, включает этапы, стадии и результаты взаимодействия субъектов образовательного процесса. Понятие «адаптированность» в нашем исследовании отражает результативную сторону процесса адаптации. Взаимодействие предполагает диагностику студентов-первокурсников для выявления лиц с особыми образовательными потребностями и проблем, с которыми они сталкиваются, став студентами; выбор и реализацию видов адаптации для таких молодых людей; укрепление их здоровья [Скамьянова, 2017, c. 372-373].

Став студентом, молодой человек вступает в новую для себя информационно-образовательную среду, сам становится ее частью. Профессиональную среду вуза можно считать «совокупностью предметно-пространственного, поведенческого, событийного и информационного культурного окружения» [Борытко, 2005, с. 71]. Н.М. Борытко, цитируя мнение психолога В.А. Климова, считает, что эта среда не сможет стихийным образом сформироваться в наилучшем варианте. 


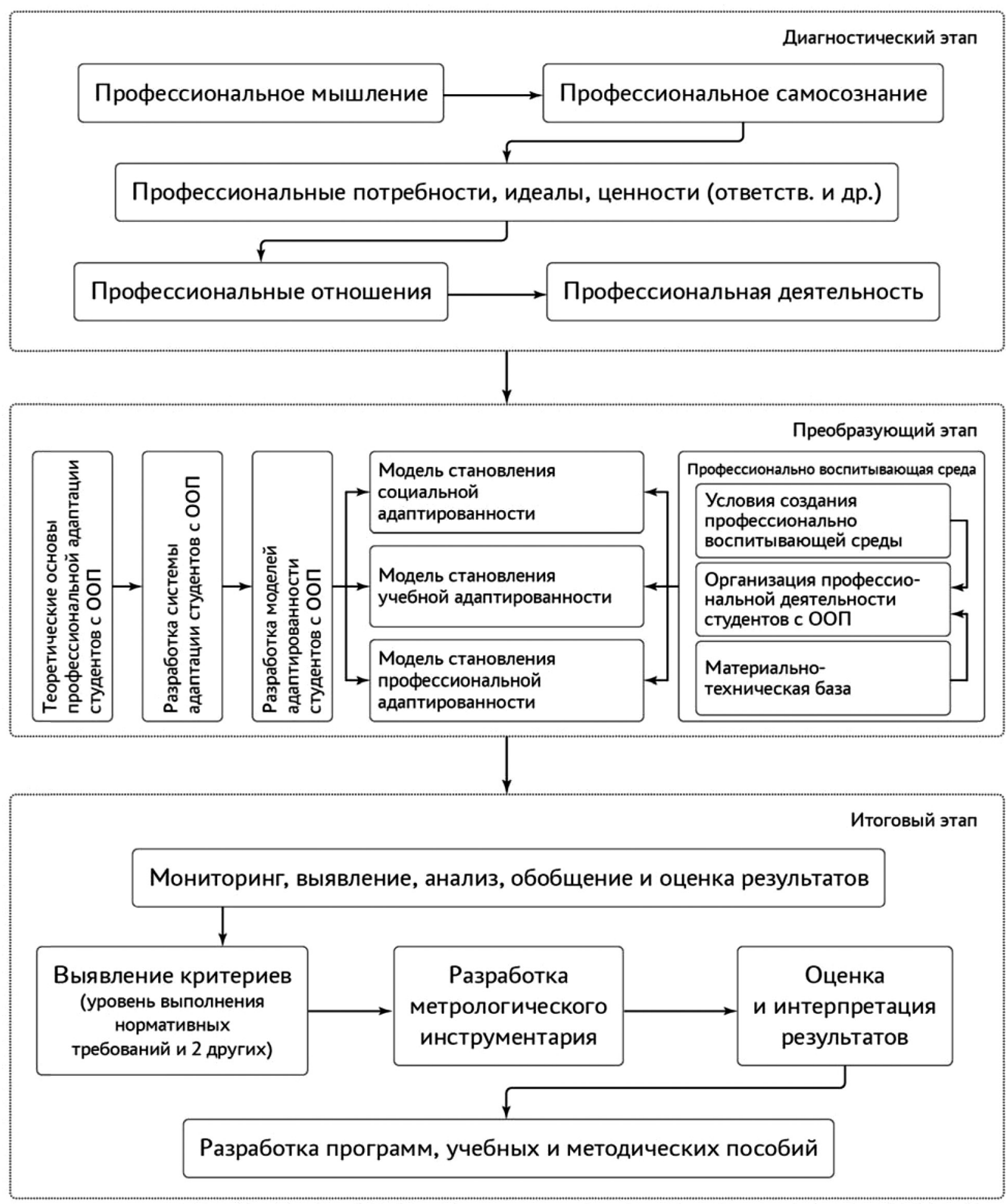

Pис. 1. Модель процесса формирования профессиональной культуры студентов с ООП

Fig. 1. Model of professional culture formation process of students with special educational needs

Ученый, описывая содержание и методы профессионального воспитания, приводит ряд существенных отличий между образовательной средой школы и образовательной средой вуза. Выделим особенно важные отличия, без которых, по мнению ряда авторов, например В.И. Загвязинского, В.А. Якунина, А.П. Тряпицыной, и др., информационно-образовательная среда не будет профессионально воспитывающей, и назовем их условиями. 


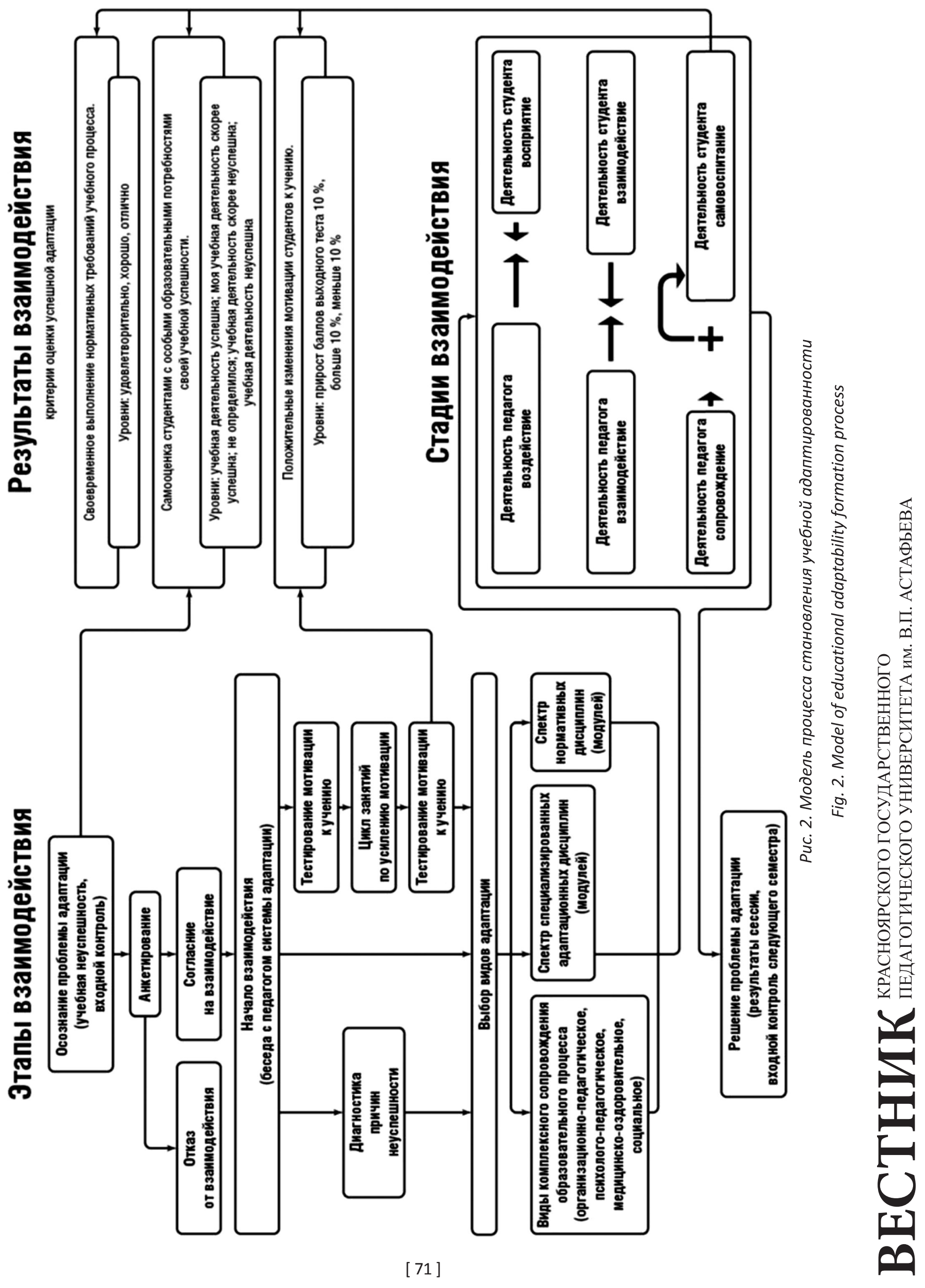


Условия создания профессионально воспитывающей среды. Учет преподавателем особенностей аудитории: уровня профессиональной подготовки, состояния здоровья, психологических характеристик и интересов студентов с ООП. Оказание таким студентам педагогической помощи в становлении их профессионального достоинства. Подготовка студентов с ООП к реальной профессиональной деятельности путем активного поиска места работы и форм специализации для адаптации к трудовой деятельности [Борытко, 2005, с. 76]. В дополнение к названным условиям выделим пожелание Я.А. Коменского об оформлении тех помещений вуза, где может находиться студент, специальным образом, чтобы «привлекать к восприятию внешние чувства» [Коменский, 1982, с. 349]. Когда молодой человек будет иметь возможность «сам осмотреть все» [Коменский, 1982, с. 390]: стенды и видеопрезентации, исходные материалы, инструменты, готовые изделия, которые можно осязать, - то, говоря образным языком Я.А. Коменского, вуз будет для него «служить театром вселенной» [Коменский, 1982, с. 390]. Заключительным условием будет важная рекомендация великих педагогов о том, что студенту необходимо активно общаться с наставниками, консультантами, представителями администрации кафедр и факультетов по всем интересующим его вопросам [Коменский, 1982, с. 371], чтобы научиться самостоятельно рассуждать [Ушинский, 1949, с. 249] и из полученных знаний выводить новые [Коменский, 1982, с. 371]. Например, студента с хроническим заболеванием интересуют санитарно-гигиенические условия, в которых осуществляется та или иная деятельность по выбранной им специальности. Эти вопросы возникают у него во время первых встреч с педагогами вуза. Получив исчерпывающие ответы, студент с ООП выражает своим наставникам устную и письменную (тестовые опросы) благодарность.

Экспериментальная проверка предложенных условий.

Экспериментальная проверка подтвердила востребованность предложенных условий создания профессионально воспитывающей среды для студентов с особыми образовательными потребностями. Эффективность профессиональной деятельности оценивается тремя основными критериями: профессиональной продуктивностью, профессиональной идентичностью и профессиональной зрелостью [Поваренков, 2013, с. 162] специалиста. Для студентов такими критериями можно считать уровень выполнения обучающимся нормативных требований учебного процесса, степень удовлетворенности выбором профессии, профессиональную самооценку [Бурлакова ${ }^{19}, 2012$, c. 292], учитывающую содержание «конкретной ситуации профессионального развития» [Поваренков ${ }^{20}, 1999$, с. 8].

Результаты анализа повышения учебной успешности студентов с ООП трех факультетов политехнического университета свидетельствуют о том, что их профессиональная продуктивность возросла. От 55 до 70 \% таких студентов после одного семестра взаимодействия с педагогами в рамках системы адаптации повысили свою учебную успешность до нормативного уровня (табл. 1). Другая часть студентов воспользовалась каникулярным временем и к началу следующего семестра достигла нормативного уровня. Количество студентов, значительно отстающих от нормативных требований, уменьшилось до 5-10 \%. Для сравнения в таблице представлены результаты учебной деятельности обучающихся с ООП, которые не участвовали в адаптационном взаимодействии. Их учебную успешность характеризует строка «Отчислены по результатам сессии», таких студентов с ООП оказалось $45 \%$. Среди тех студентов, которые не участвовали в адаптационном взаимодействии, одобряют свой выбор профессии только 10 \% респондентов. После адаптационного взаимодействия удовлетворенность выбранной специальностью заметно повышается (табл. 2).

\footnotetext{
19 Бурлакова Т.В. Индивидуализация профессиональной подготовки студентов в современном педагогическом вузе: дис. ... д-ра пед. наук. Ярославль: ГПУ, 2012. 372 с.

20 Поваренков Ю.П. Профессиональное становление личности: дис. ... д-ра психолог. наук. Ярославль: ГПУ, 1999. 359 с.
} 
Повышение учебной успешности студентов с ООП, в \% от общего числа респондентов

таблица 1

Table 1

Increasing of academic success of students with special educational needs, $\%$ of the total number of respondents

\begin{tabular}{|l|c|c|c|c|}
\hline \multicolumn{1}{|c|}{ Уровень успешности, \% } & \multicolumn{2}{|c|}{$\begin{array}{c}\text { До взаимодействия, } \\
\text { в среднем по трем } \\
\text { факультетам }\end{array}$} & \multicolumn{3}{|c|}{$\begin{array}{c}\text { После взаимодействия, } \\
\text { по факультетам }\end{array}$} \\
\cline { 3 - 5 } & ФПММ & АКФ & МТФ \\
\hline $\begin{array}{l}\text { Сессию сдали в нормативные сроки } \\
\text { «без троек» }\end{array}$ & 0 & 30 & 25 & 20 \\
\hline Сессию сдали в нормативные сроки & 30 & 20 & 40 & 30 \\
\hline $\begin{array}{l}\text { Сессию сдали на две недели позже } \\
\text { нормативных сроков }\end{array}$ & 5 & 10 & 5 & 5 \\
\hline $\begin{array}{l}\text { Сессию сдали на четыре недели } \\
\text { позже нормативных сроков }\end{array}$ & 20 & & & \\
\hline Отчислены по результатам сессии & 45 & 0 & 0 & 0 \\
\hline
\end{tabular}

Предложенные в исследовании педагогические условия создания профессионально воспитывающей среды для студентов с ООП повлияли и на профессиональную зрелость этих лиц: почти в два с половиной раза увеличилось среднее

значение балла, характеризующего профессиональную самооценку студента с особыми образовательными потребностями, от 10,07 до 24,50 [Скамьянова, 2018, с. 170].

Таблица 2

Степень удовлетворенности студентами своей профессией, в \% от числа респондентов

Table 2

Satisfaction of students with their profession, $\%$ of respondents

\begin{tabular}{|l|c|c|}
\hline \multicolumn{1}{|c|}{ Степень удовлетворенности } & Студенты, окончившие первый курс & Студенты старших курсов \\
\hline Специальность нравится & 54 & 55 \\
\hline Скорее нравится & 13 & 39 \\
\hline Не определился & 20 & 6 \\
\hline Скорее не нравится & 0 & 0 \\
\hline Специальность не нравится & 13 & 0 \\
\hline
\end{tabular}

Заключение. Предложенные педагогические условия действительно способствуют формированию профессиональной культуры у студентов с особыми образовательными потребностями, в том числе определенных способов поведения, позволяющих им справляться с адаптационными трудностями, укреплять здоровье и успешно учиться. Выполненное исследование убедило нас в том, что для студентов с ООП необходимо создавать профессионально воспитывающую среду. Она является условием успешной профессиональной адаптации таких студентов, способствует формированию у них профессиональной культуры, в том числе умения укреплять свое здоровье. Из 228 ре- спондентов, участвовавших в исследовании, об улучшении самочувствия сообщают до одной трети студентов с ООП. Не менее двух третей студентов, участвовавших в адаптационном взаимодействии один семестр, повышают свою учебную успешность до нормативного уровня. После семи семестров взаимодействия студенты с ООП осуществляют смену познавательных потребностей на профессиональные [Вербицкий, Ларионов, 2009, с. 129], корректируют выбор специальности и осознанно повышают учебную успешность до запланированного ими уровня («хорошо», «хорошо и отлично»). Большинство из них осваивают избранную специальность с удовлетворением своим выбором. 


\section{Библиографический список}

1. Агаджанян Н.Л., Тель Л.З., Циркин В.И., Чеснокова С.А. Физиология человека. М.: Медицинская книга; Н. Новгород: НГМА, 2003. $528 \mathrm{c}$.

2. Беленчук Л.Н. История отечественной педагогики: учеб. пособие М.: Изд-во ПСТГУ, 2005. 182 c.

3. Борытко Н.М. Система профессионального воспитания в вузе: учеб.-методич. пособие / науч. ред. Н.К. Сергеев. М.: АПКиПРО, 2005. $120 \mathrm{c}$.

4. Вербицкий А.А., Ларионова О.Г. Личностный и компетентностный подходы в образовании: проблемы интеграции. М.: Логос, 2009. 336 с.

5. Дистервег. Избранные педагогические сочинения. М.: Гос. учеб.-пед. изд-во Министерства просвещения РСФСР, 1956. С. 374.

6. Ивахненко Г.А. Здоровьесберегающие технологии в российских вузах // Вестник института социологии. 2013. № 6. С. 99-111.

7. Коменский Я.А. Избранные педагогические сочинения: в 2 т. М.: Педагогика, 1982. Т. 1. $656 \mathrm{c.}$

8. Локк. М.: Издательский дом Шалвы Амонашвили, 2000. С. 224. (Антология гуманной педагогики).

9. Лубовский В.И Особые образовательные потребности [Электронный ресурс] // Психологическая наука и образование psyedu.ru. 2013. № 5. URL: http://psyedu.ru/ journal/2013/5/Lubovskiy.phtml (дата обращения: 29.03.2018).

10. Мудрик А.В. Социальная педагогика: учебник для студ. пед. вузов / под ред. В.А. Сластенина. 3-е изд., испр. и доп. М.: Академия, 2002. 200 c.

11. Никуленкова О.Е. Предупреждение внутриличностных конфликтов студентов с учетом специфики гендерной идентичности в условиях вуза // Ежемесячный научный журнал. 2015. № 4 (9), ч. 4. С. 148-150.

12. Пискун О.Е. Влияние особенностей интеллекта на адаптацию студентов к обучению в техническом вузе // Ученые записки университета им. П.Ф. Лесгафта. 2011. № 11. С. 123-125.
13. Поваренков Ю.П. Уточнение предмета, метода и основных задач психологии профессионального становления личности // Ярославский педагогический вестник. 2013. № 2. С. 156-164.

14. Скамьянова Т.Ю. Адаптационное сопровождение процесса обучения студентов с особыми образовательными потребностями // Вестник Брянского государственного университета. Сер.: Педагогические науки. 2017. № 1. С. 368-374.

15. Скамьянова Т.Ю. Анализ учебной успешности студентов-первокурсников виктимного типа поведения // Стандарты и мониторинг в образовании. 2012. № 5. С. 23-24.

16. Скамьянова Т.Ю. Приоритетные направления профессиональной адаптации студентов с особыми образовательными потребностями // Вестник Нижегородского университета им. Н.И. Лобачевского. Сер.: Социальные науки. 2018. № 2 (50). С. 163-171.

17. Скамьянова Т.Ю. Условия адаптации студентов с особыми образовательными потребностями к образовательному процессу вуза // Вестник Ленинградского государственного университета им. А.С. Пушкина. 2016. № 4, ч. II. С. 246-255.

18. Ушинский К.Д. Собрание сочинений: в 11 т. М.: Изд-во Академии педагогических наук, 1949. Т. 7. 359 с.

19. Ушинский К.Д. Собрание сочинений: в 11 т. Человек как предмет воспитания. М.: Издво Академии педагогических наук, 1950. Т. 8. 769 c.

20. Фролова Н.И., Белокриницкая Т.Е., Белозерцева Е.П. Гендерное поведение риска как основной триггерный фактор гинекологической заболеваемости студенток // Бюллетень восточно-сибирского научного центра СО РАМH. 2012. № 2-2. С. 102-105. 30 позиц.

21. Шац И.К., Калягин В.А., Овчинникова Т.С. Философские основы здоровьесберегающей педагогики // Вестник Ленинградского государственного университета им. А.С. Пушкина. 2016. № 4, ч. II. С. 316-319. 
22. Шмитц Ж. Я жду ребенка / пер. с фр. В.А. Колягина. М.: Эксмо, 2008. 272 с.

23. Яковлев Е.В. Педагогическая концепция: методологические аспекты построения. М.: ВЛАДОС, 2006. 239 с.

24. Cotts E. et al. A STEM program focused on transfer student success at Binghamton university. Proceedings Frontiers in Education Conference, FIE, 2016. P. 1-4. DOI: 10.1109/ FIE.2016.7757551

25. Koca-Atabey M. Re-visiting the role of disability coordinators: the changing needs of disabled students and current support strategies from a UK university. European Journal of Spe- cial Needs Education, 2016. P. 137-145. DOI: 10.1080/08856257.2016.1254969

26. Mehr K.E., Daltry, R. Examining Mental Health Differences between Transfer and Nontransfer University Students Seeking Counseling Services. Journal of College Student Psychotherapy, 2016. P. 146-155. DOI: 10.1080/87568225.2016.1140996

27. Skamyanova T.Yu., Kosolapova L.A. Pedagogically Controlled Conditions for Adapting Students with Special Educational Needs to Their Studies As a possibility of Training to be Transferred to The Desired University // Man In India (Scopus). 2017. № 97 (5). P. 145-157. 


\section{CONDITIONS FOR CREATING A PROFESSIONAL EDUCATIONAL ENVIRONMENT FOR STUDENTS WITH SPECIAL EDUCATIONAL NEEDS}

\section{T.Yu. Skamyanova (Perm, Russian Federation)}

\section{Abstract}

Problem and purpose. The urgency of the problem of successful adaptation of students with special educational needs to study at a technical University is determined by the requirement of the formation of professional competencies of students laid down in the regulations (Federal Education Act, order of the Ministry of Education). That includes the competitiveness of such students in the world job market and the ability to perform innovative management.

The purpose of the present study is to substantiate the proposed pedagogical conditions that contribute to the formation of professional culture of students with special educational needs, including the ability to strengthen their health, which contributes to their successful professional adaptation, in general, and increase educational productivity, in particular.

The analysis of pedagogical literature shows the lack of study of professional adaptation of students with special educational needs at technical university.

The methodology of the study is based on anthropological approach in education (K.D. Ushinsky, O.S. Grebenyuk, N.M. Borytko et al.); as well as the idea of health-saving, competence, comprehensive and system-

\section{References}

1. Agadzhanyan N.L., Tel L.Z., Tsirkin V.I., Chesnokova S.A. Physiology of Man. Moscow; N. Novgorod, 2003. 528 p.

2. Belenchuk L.N. History of Russian Pedagogy. Moscow, 2005. 182 p.

3. Borytko N.M. The System of Professional Education at the University. Moscow, 2005. 120 p.

4. Verbitskiy A.A., Larionova O.G. Personal and Competence Approaches in Education: Problems of Integration. Moscow, 2009. 336 p.

5. Disterveg. Selected Pedagogical Works. Moscow, 1956. 374 p.

6. Ivakhnenko G.A. Health-Saving Technologies in Russian Universities / / Bulletin of the Institute of Sociology. 2013. No. 6. P. 99-111. atic approaches to the implementation of psychological and pedagogical research.

The results. The article presents a model of the process of formation of professional culture of students with special educational needs and defines the conditions for creating a professional educational environment for them using pedagogical technologies of contextual learning, teaching through learning and multi-level learning. Experimental test of proposed educational conditions has confirmed the effectiveness of the interaction between the subjects of the educational process.

Conclusion. The proposed pedagogical conditions really contribute to the formation of professional culture of students with special educational needs, including certain behaviors that allow them to cope with adaptation difficulties, improve their health and learning skills. Up to one third of students with special educational needs of 228 respondents who participated in the study, report improving their health. The study convinced us that it is necessary to create a professional educational environment for such students.

Keywords: Education Act, students with special educational needs, professional adaptation to learning, educational technologies, professional culture.

7. Komenskiy Ya.A. Selected Pedagogical Works. Pedagogics. Moscow, 1982. Vol. 1. 656 p.

8. Lokk. Anthology of Humane Pedagogy. Moscow, 2000. P. 224.

9. Lubovskiy V.I. Special Educational Needs [Electronic resource] / / Psychological Science and Education. 2013. No. 5. URL: http://psyedu.ru/ journal/2013/5/Lubovskiy.phtml (date of access: 29.03 .2018$)$.

10. Mudrik A.V. Social Pedagogics. Moscow, 2002. $200 \mathrm{p}$.

11. Nikulenkova O.E. Prevention of Intrapersonal Conflicts of Students Taking Into Account the Specifics of Gender Identity in the University // Monthly Scientific Journal. 2015. No. 4 (9), p. 4. P. 148-150. 
12. Piskun O.E. The Influence of Intelligence Features on the Adaptation of Students to Study at a Technical University // Scientific notes of the P.F. Lesgaft University. 2011. No. 11. P. 123-125.

13. Povarenkov Yu.P. Clarification of the Subject, Method and Main Tasks of Psychology of Professional Formation of Personality // Yaroslavl Pedagogical Bulletin. 2013. No. 2. P. 156-164.

14. Skamyanova T. Yu. Adaptive Support of the Learning Process of Students with Special Educational Needs / / Bulletin of the Bryansk State University. Pedagogical Sciences Series. 2017. No. 1. P. 368-374.

15. Skamyanova T. Yu. Analysis of Educational Success of First-Year Students of Victim Behavior // Standards and Monitoring in Education. 2012. No. 5. P. 23-24.

16. Skamyanova T. Yu. Priority Directions of Professional Adaptation of Students with Special Educational Needs / / Bulletin of Nizhny Novgorod University named after N.I. lobachevsky. Social Sciences Series. No. 2 (50). 2018. P. 163-171.

17. Skamyanova T. Yu. Conditions of Adaptation of Students with Special Educational Needs to the Educational Process of the University // Bulletin of the Leningrad State University named after A.S. Pushkin. 2016. No. 4, p. 2. P. 246-255.

18. Ushinskiy K.D. Collected Works. Moscow, 1949. Vol. 7. 359 p.

19. Ushinskiy K.D. Collected Works. Moscow, 1950. Vol. 8: Man as a Subject of Education. 769 p.

20. Frolova N.I., Belokrinitskaya T.E., Belozertseva E.P. Gender Risk Behavior as the Main Trigger Factor of Gynecological Morbidity of Students // Bulletin of the East Siberian Scientific Center of
Siberian Department of the Russian Academy of Medical Sciences. 2012. No. 2-2. P. 102-105.

21. Shats I.K., Kalyagin V.A., Ovchinnikova T.S. Philosophical Foundations of Health-Saving Pedagogy // Bulletin of the Leningrad State University named after A.S. Pushkin. 2016. No. 4, p. II. P. 316-319.

22. Shmitts Zh. I'm expecting a Baby. Moscow, 2008, 272 p.

23. Yakovlev E.V. Pedagogical Concept: Methodological Aspects of Construction. Moscow, 2006. 239 p.

24. Cotts E. et al. A STEM program focused on transfer student success at Binghamton university. Proceedings Frontiers in Education Conference, FIE, 2016. P. 1-4; DOI: 10.1109/ FIE.2016.7757551

25. Koca-Atabey, M. Re-visiting the role of disability coordinators: the changing needs of disabled students and current support strategies from a UK university. European Journal of Special Needs Education, 2016. P. 137-145. DOI: 10.1080/08856257.2016.1254969

26. Mehr, K.E., Daltry, R. Examining Mental Health Differences between Transfer and Non-transfer University Students Seeking Counseling Services. Journal of College Student Psychotherapy, 2016. P. 146-155. DOI: 10.1080/87568225.2016.1140996

27. Skamyanova T.Yu., Kosolapova L.A. Pedagogically Controlled Conditions for Adapting Students with Special Educational Needs to Their Studies as a possibility of Training to be Transferred to The Desired University // Man In India (Scopus). 2017. No. 97 (5). P. 145-157. 